EDUR • Educação em Revista. 2021; 37:e20527

DOI: http://dx.doi.org/10.1590/0102-469820527

i https://creativecommons.org/licenses/by/4.0/

ARTIGO

\title{
ABANDONO DOCENTE NA REDE MUNICIPAL DE EDUCAÇÃO DO RIO DE JANEIRO
}

\author{
KARINA CARRASQUEIRA ${ }^{2}$ \\ HTTP://ORCID.ORG/0000-0002-6699-7814 \\ MARIANE KOSLINSKI \\ https://orcid.org/0000-0002-9644-5041 ${ }^{3}$
}

\begin{abstract}
RESUMO: A retenção de professores é um desafio enfrentado por diversas redes educacionais no mundo inteiro, e tem impactos para os sistemas escolares, para escolas e para os alunos. Este artigo teve por objetivo investigar os fatores associados ao abandono docente na rede municipal do Rio de Janeiro. Utilizou bases de dados provenientes da Secretaria Municipal do Rio de Janeiro (SME-RJ) e do Instituto Nacional de Estudos e Pesquisas Educacionais Anísio Teixeira (INEP) que permitiram acompanhar, entre 2012 e 2016, a trajetória de 3594 professores que tomaram posse entre 2009 e 2011. As análises utilizaram modelos de regressões logísticas para estimar a probabilidade de o professor abandonar a rede. Os resultados indicam que professores mais jovens e com maior nível de escolaridade apresentam maior probabilidade de abandonar a rede. Além disso, o perfil do alunado, a experiência de mudar de escola e as pressões de uma política de responsabilização escolar, que vigorava no período em que a pesquisa foi realizada, também se mostraram fatores associados à probabilidade do docente abandonar a rede.
\end{abstract}

Palavras-chave: abandono docente, trajetória docente, carreira docente, educação básica, regressão logística

\section{TEACHER ATTRITION IN RIO DE JANEIRO MUNICIPAL EDUCATION SYSTEM}

ABSTRACT: Teacher retention is a challenge faced by several education systems worldwide, and has impacts for school systems, schools, and students. This article aimed to investigate the factors associated with teacher attrition in the municipal system of Rio de Janeiro. It used databases from the Municipal Secretariat of Rio de Janeiro (SME-RJ) and the National Institute of Educational Studies and Research Anísio Teixeira (INEP) that allowed to follow, between 2012 and 2016, the trajectory of 3594 teachers who took office between 2009 and 2011. The analyses used logistic regression models to estimate the

1 O presente trabalho foi realizado com apoio da Coordenação de Aperfeiçoamento de Pessoal de Nível Superior - Brasil (CAPES) - Código de Financiamento 001

2 Pós-doutoranda (PNPD) no Departamento de Educação da PUC-Rio. Rio de Janeiro, RJ, Brasil. $<$ klcarrasqueira@gmail.com>

${ }^{3}$ Universidade Federal do Rio de Janeiro (UFRJ). Rio de Janeiro, RJ, Brasil. <mckoslinski@gmail.com> 
probability of the teacher leaving the system. The results indicate that younger and more highly educated teachers are more likely to leave the system. In addition, the profile of the student body, the experience of changing schools, and the pressures of a school accountability policy, which was in force during the period when the research was carried out, were also factors associated with the probability of the teacher leaving the system.

Keywords: teacher attrition, teacher trajectory, teacher career, basic education, logistic regression

\section{ABANDONO DE DOCENTES EN LA RED MUNICIPAL DE EDUCACIÓN DE RIO DE JANEIRO}

RESÚMEN: La retención de docentes es un desafío que enfrentan varias redes educativas en todo el mundo y tiene un impacto en los sistemas escolares, las escuelas y los estudiantes. Este artículo tuvo como objetivo investigar los factores asociados con el abandono de docentes en la red municipal de Río de Janeiro. Utilizó bases de datos de la Secretaría Municipal de Río de Janeiro (SME-RJ) y del Instituto Nacional de Estudios e Investigaciones Educativas "Anísio Teixeira" (INEP/MEC) que permitieron monitorear, entre 2012 y 2016, la trayectoria de 3594 docentes que se unieron a la red entre 2009 y 2011. Los análisis utilizaron modelos de regresión logística. Para estimar la probabilidad de que el profesor abandone la red. Los resultados indican que los maestros más jóvenes y más educados tienen más probabilidades de abandonar la red. Además, el perfil del alumno, la experiencia de cambiar de escuela y las presiones de una política de responsabilidad escolar, que estuvo en vigencia durante el período en que se llevó a cabo la investigación, también mostraron factores asociados con la probabilidad de que el maestro abandone la red.

Palabras clave: abandono de docentes, trayectoria docente, carrera docente, educación básica, regresión logística 


\section{INTRODUÇÃO}

Pesquisas nos EUA indicam que cerca de um quarto dos novos docentes abandonam a rede educacional depois de 5 anos da sua entrada (BOYD et al., 2008; RONFELDT et al., 2011). Visto que os sistemas educacionais realizam investimentos para atrair professores e para lhes oferecer formação continuada, gera-se um problema quando o abandono de professores recém contratados gera altas taxas de rotatividade docente nas escolas. Isso porque, como argumentam Allensworth, Ponisciak e Mazzeo (2009) grande rotatividade docente prejudica a continuidade do trabalho pedagógico da escola e diversos estudos indicam que a estabilidade do corpo docente é uma característica de escolas eficazes.

Estudos observaram que, para as escolas que atendem crianças de Nível Socioeconômico (NSE) mais baixo e com menor performance nas avaliações, as taxas de abandono docente tendem a ser mais elevadas (HANUSHEK et al., 2005; BOYD et al., 2008). Se escolas que atendem a um público específico apresentam maior rotatividade docente que outras, essa variação pode gerar desigualdades entre as escolas de uma rede (CLOTFELTER, LADD \& VIDGOR, 2010; MANSFELD, 2012). Assim, o abandono docente em si não é ruim, mas ele se torna muito prejudicial se esses professores forem os mais eficazes e estiverem concentrados em escolas com características específicas (BOYD et al., 2008).

A identificação da capacidade/dificuldade de uma rede de ensino em reter seus professores, do perfil dos docentes que mais frequentemente abandonam e das escolas que mais perdem professores torna-se importante para informar estratégias no sentido de aumentar a estabilidade do corpo docente, evitar a perda dos professores mais eficazes e para que escolas com maior concentração de alunos vulneráveis sofram, mais frequentemente, com a falta de professores.

No Brasil, são poucos os estudos que investigaram o fenômeno do abandono docente, sendo a maior parte deles qualitativos (LAPO; BUENO, 2002, 2003; LEMOS, 2009; REBOLO, 2012; SOUTO, 2013; PAZ, 2013; XAVIER; BARBOSA, 2015; PEREIRA; OLIVEIRA, 2016, 2018; CARDOSO, 2018 ; CARLOTTO, CÂMARA; OLIVEIRA, 2019). Ainda assim, estudos realizados no contexto brasileiro apontam a rotatividade docente como um fator para a manutenção das desigualdades educacionais entre escolas com alunado de perfis socioeconômicos diferentes (TORRES et al., 2008; KASMIRSKI, 2012; ALVES et al., 2013). Além disso, escolas que atendem a população mais vulnerável, em geral, sofrem mais com perdas e falta de professores.

Este trabalho, que apresenta parte dos resultados encontrados na tese de doutorado de Carrasqueira (2018), tem como objetivo principal investigar fatores associados ao abandono docente. Especificamente, este artigo pretende: a) observar tendências de retenção/abandono de professores da rede de educação carioca e b) identificar características dos docentes e das escolas mais associadas ao abandono da rede. Para tanto, o presente trabalho utiliza dados cedidos pela Secretaria Municipal de Educação do Rio de Janeiro e dados obtidos no portal eletrônico do Instituto Nacional de Estudos e Pesquisas Educacionais Anísio Teixeira (INEP), com informações sobre professores, alunos e escolas. A combinação destas fontes de dado possibilitou, de um lado, observar o abandono de professores na rede durante o período de 2012 a 2016 e, de outro, realizar análises multivariadas que associam este fenômeno às características dos docentes e da última escola em que estavam lotados.

Este artigo, além desta introdução, está dividido em 7 seções. As duas primeiras discutem estudos internacionais e nacionais sobre abandono docente. A terceira seção apresenta as regras de ingresso e permanência e as pressões de políticas recentes de responsabilização adotadas pela rede municipal do Rio de Janeiro que podem impactar a decisão dos professores de abandonar a rede. A seção seguinte aborda os aspectos metodológicos do estudo: desenho da pesquisa, bases de dados, variáveis e modelos estatísticos utilizados. Na quinta parte, apresentaremos e discutiremos os resultados de análises descritivas e multivariadas a partir da estimação de modelos de regressão logística. Por fim, o artigo tece algumas conclusões sobre os fatores associados ao abandono da rede e a relevância desse tipo de estudo para a elaboração de políticas públicas de retenção dos professores e propõe perspectivas para novos estudos sobre o tema. 


\section{FATORES ASSOCIADOS AO ABANDONO DOCENTE: LITERATURA INTERNACIONAL}

O abandono docente é caracterizado como a saída voluntária do professor da carreira docente, desconsiderando assim, fatores como aposentadoria ou falecimento. No presente trabalho, frente às limitações dos dados utilizados que serão descritas mais adiante, estamos observando o abandono exclusivamente como a saída do docente de uma rede pública específica e não necessariamente, da carreira.

Pesquisas como as de Boyd et al. (2008), Allensworth, Ponisciak e Mazzeo (2009) e Ronfeldt et al. (2011), nos EUA, observaram que a maior parte dos professores abandonam a rede ainda nos primeiros 5 anos de profissão. West e Chingos (2009) verificaram que em 5 anos cerca de $1 / 3$ dos professores novos já abandonaram a rede da Flórida, mais do que o número de professores que permaneceram na mesma escola onde inicialmente foram designados.

Quando os professores que abandonam uma rede estão concentrados em algumas escolas, este fenômeno também gera uma rotatividade de professores maior nestas escolas. Esses dados são relevantes quando pesquisas como as de Ronfeldt, Leob e Wyckoff (2013) e Atteberry, Leob e Wyckoff (2017) indicam que a rotatividade docente gera impacto negativo para a aprendizagem dos alunos. Turmas que são expostas a professores novatos na profissão, na rede de ensino e na escola apresentam resultados significativamente menores do que turmas com professores já integrados à escola.

Os fatores que levam professores a abandonar a profissão são agrupados pela literatura sobre o tema como características do docente (demográficas, qualificação, experiência, satisfação profissional, auto eficácia), fatores relacionados à escola (composição socioeconômica do alunado, clima escolar, liderança da gestão, segmento, indicadores educacionais da escola, localização) e fatores relacionados ao sistema (salário, pressões de políticas de responsabilização, programas de apoio à professores novatos).

Sass et al. (2012) realizaram uma pesquisa no Texas utilizando dados de mais de $200 \mathrm{mil}$ professores que ingressaram nas escolas públicas ou charter schools do estado no período de 1988 a 2010, na qual buscaram identificar fatores associados ao abandono docente. Os autores realizaram análises de sobrevivência que indicaram que professores que ingressam na profissão muito jovens, homens, negros (afro americanos) e estrangeiros têm taxas de risco maiores de abandonar a rede se comparados com outras categorias.

Já no que diz respeito às características das escolas ou sistema educacional do Texas, os pesquisadores observaram primeiro, que a implantação da política de responsabilização ${ }^{4}$ aumentou o risco de os professores abandonarem a profissão. Contudo, o estudo não verificou se as pressões de tais políticas foram seguidas por maior abandono de professores menos qualificados/menos eficazes ou de professores mais eficazes. Adicionado a isso, fatores escolares como alto desempenho da escola na avaliação externa, ser escola pública (ao invés de charter) e ser professor primário (elementary teacher) impactavam diminuindo a taxa de risco de o professor abandonar a rede. De forma similar, Ryan et al. (2017) investigaram o impacto das pressões geradas por políticas de responsabilização na intenção de abandono por parte dos docentes. No entanto, este estudo, realizado com professores de três estados norte-americanos, não encontrou uma correlação entre as pressões relatadas pelos professores e um aumento na intenção de abandono da profissão - embora tenha encontrado relação com a intenção de mudar de escola.

Borman e Dowling (2008) realizaram uma meta-análise com 34 pesquisas norte-americanas que buscaram investigar fatores associados ao abandono ou retenção docente realizadas entre 1980 e 2005. Sobre as características demográficas dos professores, a meta-análise indicou que mulheres apresentam maior chance do que homens de abandonar, assim como minorias étnicas em relação aos brancos, professores que ingressaram na profissão mais novos em relação aos que ingressaram mais velhos, casados em comparação com solteiros e professores que têm filhos comparados com quem não tem filho algum.

\footnotetext{
${ }^{4}$ Políticas de responsabilização ou, do inglês, accountability policies, são um tipo de política de avaliação educacional que - embora possam ter instrumentos e desenhos distintos - têm como características comuns a testagem sistemática do rendimento dos alunos, o estabelecimento de metas a serem atingidas e mecanismos de premiação e/ou punição para escolas, gestores, professores e (em alguns casos) alunos. Para uma explicação mais aprofundada sobre este tipo de política e em especial sobre a implementada no município do Rio de Janeiro, ver Carrasqueira (2013).
} 
Na Itália, Barbieri, Rossetti e Sestito (2010) observaram que mulheres mais jovens tinham maior chance de abandonar, mas muitas delas voltavam para a rede, o que poderia representar apenas o tempo de licença maternidade. Na mesma direção deste estudo, Allensworth, Ponisciak e Mazzeo (2009) observaram uma diferença muito pequena entre homens e mulheres que abandonaram a rede pública de Chicago.

Com relação à escolaridade e à experiência dos professores, a meta-análise de Borman e Dowling (2008) verificou que docentes com pós-graduação tinham uma maior probabilidade de sair se comparados com os docentes sem pós-graduação. E que os docentes com mais de 5 anos de experiência também apresentavam chances mais alta em comparação com professores menos experientes. E, embora tenha sido estatisticamente significante, os resultados da meta análise indicaram que as chances de um professor primário (elementary teacher) abandonar era apenas de 1,02 vezes a de um professor secundário (secondary teacher). Resultados similares foram encontrados por Dupriez, Delvaux e Lothaire (2016) na Bélgica francófona, que observaram professores novatos durante 4 anos seguidos. Os autores verificaram que os professores secundários, os homens, os professores menos qualificados e com menos experiência tinham maior probabilidade de abandonar a profissão.

As pesquisas analisadas por Borman e Dowling (2008) verificaram que escolas com maioria negra ou latina e escolas com corpo discente majoritariamente de baixo nível socioeconômico aumentam a chance de o professor abandonar a rede. Da mesma forma, professores em escola de baixa performance na avaliação externa têm chance maior de sair da escola. Contudo, pesquisas sobre rotatividade docente indicam que as condições de trabalho, o clima escolar e a liderança do diretor têm um impacto maior na decisão do professor abandonar a escola e/ou a rede de ensino do que as características do aluno (BOYD et al, 2011, LADD, 2011, GEIGER; PIVOVAROVA, 2018).

Boyd et al. (2011) investigaram, na cidade de Nova Iorque, o impacto das condições de trabalho na probabilidade de o professor abandonar a rede no primeiro ano. Já Ladd (2011) investigou, no estado da Carolina do Norte, o impacto das condições de trabalho na intenção de abandono de professores novatos. Em ambos os estudos, as variáveis mais relevantes foram a liderança da gestão e participação do professor nas decisões.

Geiger e Pivovarova (2018) buscaram entender o impacto das condições de trabalho em escolas do Arizona com alunos de alta vulnerabilidade. O resultado geral da pesquisa foi que as características dos alunos não pareciam ser significantes na decisão do professor abandonar. Para os professores nas escolas com alta porcentagem de alunos pobres, um motivador para os professores permanecerem foi ter mentoria. A meta-análise de Borman e Dowling (2008) também observou que redes e/ou escolas onde existiam mecanismos formais de apoio e mentoria para professores iniciantes, as chances de abandono diminuíam. Os autores argumentam que nos EUA é comum que professores novatos sejam designados para tarefas mais difíceis e que recebam menos recursos do que professores veteranos.

Da mesma forma, Kalogrides, Loeb e Béteille (2012) ao pesquisar a alocação dos docentes em turma, no distrito de Miami, observaram que professores de minorias étnicas e mulheres eram mais designados para turmas com baixo desempenho, além disso, docentes novatos designados para turmas com problemas de comportamento tendiam a sair da escola, fato que não era observado se o professor fosse mais experiente.

Ronfeldt e McQueen (2017) realizaram um estudo quantitativo com dados dos EUA e investigaram se diversos tipos de apoio (seminários, mentoria, planejamento coletivo, suporte da gestão, horário reduzido, ajuda extra) à professores iniciantes tinha impacto no abandono docente. Os autores encontraram que todos os tipos de apoio diminuíam as chances de abandono em relação a não ter apoio algum. Os mecanismos que explicam tal relação podem ser compreendidos a partir do estudo de Buchanam et al. (2013), realizado na Austrália com professores iniciantes. A partir do relato dos docentes em entrevistas, os pesquisadores observaram que os professores novatos se sentiam sozinhos e sobrecarregados.

No Chile, Ávalos e Valenzuela (2016) observaram, por meio de questionário com 157 professores que abandonaram o magistério, que os principais motivos para a decisão de abandono eram, em ordem: descontentamento com as possibilidades de desenvolvimento profissional, baixos salários e insatisfação com a liderança da gestão. Pesquisas qualitativas realizadas por meio de entrevistas a 
professores nos EUA (GONZALEZ, BROWN \& SLATE, 2008), no Canadá (SAUVÉ, 2012), na Austrália (BUCHANAN et al., 2013) e nos Emirados Árabes Unidos (AL KAABI, 2005), relataram que os professores que abandonaram escolas indicaram como uma das causas o desinteresse e a indisciplina dos alunos. Outras percepções relatadas por essas pesquisas estavam relacionadas com o clima escolar e com os salários, que foram relatadas como insatisfatórios. Já no estudo de Borman e Dowling (2008) os fatores financeiros são bem mais destacados do que os fatores escolares. Salários mais baixos correspondem a uma grande chance de abandono docente, assim como a insatisfação com o salário.

Em geral, as pesquisas internacionais acharam fatores semelhantes mesmo em contexto bastante distintos. O abandono da profissão está bastante associado com sentimento de insatisfação, seja com as condições de trabalho, seja com o público da escola, seja com o próprio ambiente escolar. Neste sentido é compreensível o fato de que profissionais mais jovens tenham maior propensão a abandonar, uma vez que professores mais antigos persistiram ao desencanto da profissão.

\section{FATORES ASSOCIADOS AO ABANDONO DOCENTE: O QUE DIZEM AS PESQUISAS BRASILEIRAS}

No Brasil, a maioria das pesquisas sobre o tema buscou identificar, por meio de metodologias qualitativas, os fatores que levaram professores a abandonar a profissão (LAPO; BUENO, 2002, 2003; LEMOS, 2009; REBOLO, 2012; PAZ, 2013; SOUTO, 2013; XAVIER; BARBOSA, 2015). E, embora tenhamos muitos estudos brasileiros sobre o perfil dos professores da educação básica, são poucos os estudos que procuraram investigar, por meio de análise quantitativa, as características dos professores (CARDOSO, 2018), e das condições de trabalho (CARLOTTO, CÂMARA; OLIVEIRA, 2019) associadas ao abandono docente. De toda forma, todos estes estudos brasileiros, apresentaram grande coesão em torno dos motivos que fizeram os docentes abandonarem a profissão e estão em consonância com a literatura internacional sobre o tema.

Sobre os motivos que levam os docentes a abandonarem a profissão, Lemos (2009) entrevistou 34 professores de segundo segmento que pediram para sair da rede no ano de 2006. Os docentes pesquisados por Lemos atuaram na rede estadual como "temporário" e, portanto, não eram professores estatutários com estabilidade garantida. Ainda assim, os motivos apontados por esses docentes nas entrevistas realizadas pelo autor estão em consonância com o que encontramos na literatura como fatores relacionados com o abandono. O principal fator relatado pela maioria dos professores foi a desvalorização da profissão, que apesar de ser um conceito bastante abstrato em termos gerais, foi sendo explicado como uma sensação de desprestígio profissional no qual o professor perde sua autoridade frente aos alunos, responsáveis e sociedade, perde sua autonomia de trabalho e é desrespeitado pelo governo que implementa e descontinua políticas sem levar em conta o trabalho em sala de aula e as necessidades dos professores (LEMOS, 2009).

A indisciplina e violência dos alunos, os baixos salários e o clima escolar foram os fatores mais citados em seguida. Não sabemos se há a possibilidade de mobilidade voluntária desses professores para outras escolas da rede e, levando em conta o contexto apresentado por Torres et al. (2008), é de se esperar que os professores concursados migrem das escolas com alunos indisciplinados, em regiões de vulnerabilidade social e com clima escolar que consideram ruim, para escolas com características socioeconômicas mais favoráveis, alunos mais disciplinados e clima escolar mais favorável ao aprendizado. Desta forma, as turmas vagas para os professores temporários seriam justamente as que os professores estatutários não quiseram. Sem a possibilidade da mobilidade, a opção dos professores temporários seria permanecer nestas escolas ou abandonar a rede. Lemos (2009) não fez essa discussão, mas aponta que o número de professores efetivos que abandonaram a rede no ano pesquisado (2006) era muito pequeno, fator que o fez decidir entrevistar os temporários.

Souto (2013) investigou os motivos para o abandono com licenciandos de matemática egressos da Universidade Federal de São João Del-Rey (MG) e verificou que dos 89 que responderam ao questionário, 34 não exerciam a profissão e 13 afirmaram que pretendiam abandonar. Os principais motivos de insatisfação com o magistério relatados estavam associados com baixos salários e com desinteresse e indisciplina dos alunos. A autora não faz diferenciação entre os tipos de escolas em que os professores estavam ou estiveram, focando mais nos fatores que influenciam a decisão de abandonar. 
Paz (2013), tentando compreender as identidades construídas dos professores de matemática que permaneciam na profissão, entrevistou 9 professores da rede estadual de Minas Gerais (5 de uma escola na região central de Belo Horizonte e 4 de uma escola em uma região periférica de Belo Horizonte) e 11 professores que abandonaram a docência. Embora a autora não entre nesta análise, é interessante notar que a escola da região central, considerada uma escola de bom/alto desempenho também é, entre as duas escolas do estudo, a que tinha um quadro completo de professores efetivos e docentes com mais tempo de magistério. Outro ponto a se destacar, para os professores que abandonaram (cuja seleção foi por conveniência e tinham lecionado em redes diferentes), é que não houve diferença entre número de professores efetivos (6) e contratados (5) e a formação dos professores que abandonaram era similar a dos professores que estavam em exercício.

Rebolo (2012) e Xavier e Barbosa (2015) observaram de forma mais detalhada o processo de desencanto com a profissão, através dos relatos de duas professoras, uma de São Paulo e outra de Belo Horizonte, que as levou a abandonar o magistério. Para os autores, o abandono não ocorre de forma abrupta. É um processo construído. Lapo e Bueno (2002; 2003) já indicavam, em seu estudo na década de 1990, que o abandono se dava em um processo que se iniciava com pequenas rupturas até culminar com a ruptura total. Tal processo é observado claramente em Rebolo (2012) e Xavier e Barbosa (2015) quando as professoras relatam as constantes licenças, cada vez mais longas e mais seguidas. Em ambos os relatos, observa-se o desgaste físico e mental gerado pela indisciplina e violência (verbal e física) dos alunos e o sentimento de desamparo em relação à gestão e aos responsáveis dos alunos. A falta de condições básicas para o exercício da profissão, baixos salários e plano de carreira insatisfatório também foram importantes na decisão das professoras em abandonar as redes públicas em que estavam.

Com relação às condições de trabalho, Carlotto, Câmara e Oliveira (2019) investigaram, através de um questionário aplicado a 376 professores, 21 estressores ocupacionais que poderiam estar associados às tendências ao abandono de docente de educação infantil e fundamental de uma rede municipal da região metropolitana de Porto Alegre. Por meio de regressão linear, elas observaram que estressores relacionados com multiplicidade de papéis a desempenhar, conciliação entre trabalho e lazer e relação com o aluno eram preditores da intenção de abandono daqueles professores.

Sobre o perfil dos professores que abandonam, a monografia de Cardoso (2018) investigou características de professores do ensino médio efetivos que pediram exoneração da rede estadual de São Paulo, entre os anos de 2009 e 2017. O autor observou que professores do sexo feminino, egressos de faculdades particulares, na faixa de 31 a 40 anos e em escolas do interior do estado apresentaram maior percentual de abandono. As mulheres e professores em escolas do interior são a maioria dos professores efetivos e, portanto, era de se esperar um maior percentual de abandono. Quanto à dependência administrativa da instituição em que se graduou (pública ou privada) e da faixa de idade, o trabalho não nos permite comparar com o total de efetivos. Vale ressaltar que este trabalho visava apenas apresentar um perfil dos professores que pediram exoneração da rede, não apresentando resultados que permitissem estabelecer tendências ou fatores associados ao abandono.

Em sua pesquisa Cardoso (2018) também aplicou um questionário a 28 professores de Sociologia que abandonaram a rede estadual de São Paulo. Como o autor constata, a maioria (24) tinham formação específica para a disciplina, mais da metade possuía mestrado (14) ou doutorado (8). Interessante notar que dos 28 entrevistados, 21 saíram da rede ainda nos primeiros dois anos de ingresso, sendo que 14 abandonaram no primeiro ano. Com relação aos motivos para o abandono, Cardoso (2018) encontra relatos semelhantes aos das outras pesquisas realizadas no Brasil e no mundo: salários baixos que obrigam o professor a trabalhar em várias escolas ou a ter uma ocupação extra, precarização das condições de trabalho, falta de apoio da gestão e da colaboração dos colegas, indisciplina, violência ou desinteresse dos alunos. Na mesma direção, outros estudos que analisam as condições de trabalho de professores no contexto brasileiro no que diz respeito ao salário e carreira, embora não focalizem fatores associados ou motivos para abandono, argumentam que tais condições implicariam tanto na baixa procura pela docência como também no abandono da profissão (BARBOSA, 2011; MASSON, 2017; LOUSANO ET AL., 2010)

Neste sentido, vemos que as pesquisas em diversos contextos diferentes apresentam resultados bem parecidos, o que reforça os achados brasileiros. Contudo, nenhuma destas pesquisas realizadas no Brasil se propôs a investigar padrões do abandono de acordo com o perfil dos docentes, 
das escolas e das redes. A pesquisa de Carlotto, Câmara e Oliveira (2019), a única que se propôs a realizar uma análise de correlação, não tinha como variável dependente o abandono em si, mas a intenção do professor em abandonar. Todos os outros estudos supracitados, se concentraram em buscar junto aos professores, a partir de relatos de história de vida, entrevistas semiestruturadas ou questionários com questões abertas, explicações para o seu abandono.

\section{ASPECTOS METODOLÓGICOS E LIMITAÇÕES DOS DADOS}

\section{A Rede Municipal do Rio de Janeiro}

O presente estudo foi realizado na Rede Municipal do Rio de Janeiro, que apresenta características de menor precarização do trabalho docente se comparados com outras redes municipais no que diz respeito ao salário, plano de carreiras e número de professores concursados.

A principal forma de ingresso na rede para os cargos de Professor na rede Municipal do Rio de Janeiro é por concurso público. As vagas no concurso são designadas pelas Coordenadoria Regional de Educação (CRE) e o candidato, no momento da inscrição, escolhe a CRE que deseja. Uma vez aprovados no concurso, os professores são chamados, em ordem de classificação, para escolherem sua unidade de lotação, dentre as escolas com vagas abertas.

O plano de carreira e remuneração dos professores no município do Rio de Janeiro combina o tempo de serviço no magistério na rede e o nível de escolarização, sendo proporcionais às horas de trabalho semanais. Segundo dados do INEP, em 2014, a remuneração bruta dos docentes da rede municipal do Rio de Janeiro era de R $\$ 3.270,26$, com média de 21,3 horas de trabalho semanal. No estado do Rio de Janeiro, era a $6^{a}$ rede com pagamentos mais altos, e estava acima da média das redes municipais do Brasil que era de $\mathrm{R} \$ 2.385,66$, de forma que, embora os salários dos professores ainda estejam aquém da sua importância na sociedade, a remuneração da rede municipal do Rio de Janeiro não está entre as menos atrativas.

Neste contexto de servidores estatutários, o abandono é representado por duas situações: (i) professores que pediram exoneração; (ii) professores que abandonaram a função. A exoneração é um processo oficial no qual o docente abre mão de seu cargo e sua saída é prontamente notificada no Diário Oficial do município. Já o abandono de função se configura quando o docente tem 30 dias consecutivos de faltas não justificadas. Nas bases de dados que estamos utilizando, não temos indicados esses processos, e por isso, podemos ter professores que abandonaram - ou seja, estão há mais de 30 dias sem comparecer na escola sem justificativa - mas na base de dados aparecem como lotados na sua escola de origem.

\section{Dados e coorte}

Os dados utilizados nesta análise foram cedidos pela Coordenadoria de Recursos Humanos (CHR) da Secretaria Municipal de Educação do Rio de Janeiro (SME-RJ). Também foram utilizados dados do Censo Escolar do INEP, resultado do IDEB, resultado do Prêmio Anual de Desempenho, e dados do Sistema de Gestão Acadêmica do município do Rio de Janeiro. Assim, foi possível complementar e relacionar dados referentes aos professores, alunos e escola com maior precisão e menos dados faltantes.

Os professores que estamos observando nesse trabalho são Professores II, ou seja, professores que lecionavam no primeiro segmento do Ensino Fundamental $\left(1^{\circ}\right.$ ao $5^{\circ}$ ano $)$ e na educação infantil, e, portanto, ainda estavam no regime de cargos anterior a 2013. Como mostra a Figura 1, selecionamos os professores que ingressaram na rede nos anos de 2009, 2010 e 2011 e observamos as saídas precoces da rede entre os anos de 2012 e 2016.

Embora o ideal fosse observar o abandono desde a entrada do professor na rede, as bases de dados disponíveis para a seleção de professores só continham os docentes que estavam na rede no início de 2012. Deste modo não era possível acompanhar os docentes que entraram depois de $2012 \mathrm{e}$ não era possível observar quem saiu antes de 2012.

Figura 1: Desenho da análise do abandono. 


\section{Desenho da análise descritiva do abandono}

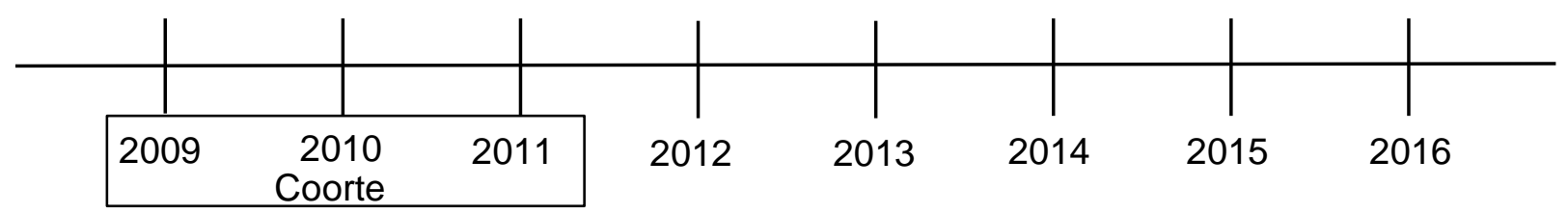

Observação das saídas da rede

Fonte: Autor, 2018.

\section{Variáveis}

O quadro 1 a seguir apresenta as variáveis utilizadas nas análises. A seleção dessas variáveis teve como base a literatura sobre o tema, discutida anteriormente. As variáveis foram divididas em dois grupos: características dos docentes e características das escolas. As características dos docentes são fixas no momento da posse, e as características das escolas são em relação à última escola em que o professor esteve lotado. Para os professores que não saíram da rede, a última escola corresponde à sua lotação em novembro de 2016.

Quadro 1: Descrição das variáveis.

\begin{tabular}{|c|c|c|c|}
\hline Variável & Descrição da variável & Formato & Fonte \\
\hline \multicolumn{4}{|c|}{ DEPENDENTE } \\
\hline Saiu da rede & $\begin{array}{l}\text { Se o professor saiu da rede } \\
(1=\text { Saiu, } 0=\text { Não saiu })\end{array}$ & $\begin{array}{l}\text { Categórica } \\
\text { nominal }\end{array}$ & Magister \\
\hline \multicolumn{4}{|c|}{ INDEPENDENTE } \\
\hline \multicolumn{4}{|c|}{ Característica docente } \\
\hline Idade & Idade do professor na data da posse & $\begin{array}{c}\text { Numérica } \\
\text { discreta }\end{array}$ & $\begin{array}{l}\text { Censo } \\
\text { Escolar }\end{array}$ \\
\hline Escolaridade & $\begin{array}{l}\text { Escolaridade do professor } \\
(1=\text { Superior, } 0=\text { Médio })\end{array}$ & $\begin{array}{c}\text { Categórica } \\
\text { nominal }\end{array}$ & Magister \\
\hline Sexo & $\begin{array}{c}\text { Sexo do professor } \\
(1=\text { Feminino, } 0=\text { Masculino })\end{array}$ & $\begin{array}{c}\text { Categórica } \\
\text { nominal }\end{array}$ & $\begin{array}{l}\text { Censo } \\
\text { Escolar }\end{array}$ \\
\hline Número de mudanças & $\begin{array}{l}\text { Quantas vezes mudou de lotação até } \\
\text { o fim do acompanhamento }\end{array}$ & $\begin{array}{c}\text { Numérica } \\
\text { discreta }\end{array}$ & Magister \\
\hline \multicolumn{4}{|c|}{ Característica da escola } \\
\hline $\begin{array}{c}\text { Índice de Nível } \\
\text { Socioeconômico (INSE) }\end{array}$ & Indicador & $\begin{array}{c}\text { Numérica } \\
\text { contínua }\end{array}$ & SGA \\
\hline $\begin{array}{l}\text { Índice de Complexidade da } \\
\text { Gestão (ICG) }\end{array}$ & Indicador & $\begin{array}{l}\text { Numérica } \\
\text { contínua }\end{array}$ & $\begin{array}{l}\text { Censo } \\
\text { Escolar }\end{array}$ \\
\hline $\begin{array}{l}\text { Índice de Desenvolvimento da } \\
\text { Educação Básica (IDEB) }\end{array}$ & IDEB da escola para o $1^{\circ}$ segmento & $\begin{array}{l}\text { Numérica } \\
\text { contínua }\end{array}$ & INEP \\
\hline $\begin{array}{l}\text { Prêmio Anual de Desempenho } \\
\text { (PAD) }\end{array}$ & $\begin{array}{l}\text { Quantas vezes a escola ganhou o } \\
\text { PAD entre } 2009 \text { e } 2016\end{array}$ & $\begin{array}{l}\text { Numérica } \\
\text { discreta }\end{array}$ & SME \\
\hline
\end{tabular}

Fonte: elaboração própria.

No que diz respeito ao perfil dos professores, foram utilizadas as seguintes variáveis: nível de escolaridade, idade, sexo e número de mudanças de lotação realizadas no período de observação (2012-2016). Para caracterizar as escolas, os modelos estimados consideraram as seguintes variáveis 
explicativas: o nível socioeconômico do corpo discente, a complexidade da gestão, o número de vezes que a escola ganhou o Prêmio Anual de Desempenho (PAD) e o IDEB da escola.

O nível socioeconômico e a complexidade da gestão são dois índices criados, por redução com o método de análise fatorial, a partir: da escolaridade dos responsáveis do aluno, cor/etnia do aluno e se o aluno ou seu responsável possuía Número de Inscrição Social (nível socioeconômico) ${ }^{5}$; do número de matrículas, do número de etapas e modalidades de ensino que a escola oferece e do número de turnos em que a escola funciona (complexidade da gestão).

O Prêmio Anual de Desempenho fazia parte da extinta política de responsabilização escolar que era praticada na rede no período da pesquisa. Esta premiação consistia no pagamento de 1 salário adicional ( $14^{\circ}$ salário) para os servidores lotados nas escolas que alcançassem as metas de IDEB e IDERio (versão carioca do IDEB) estabelecidas pela Secretaria Municipal de Educação. Esta variável visava observar a associação das pressões de responsabilização e o abandono da rede.

A variável dependente da nossa análise, chamada "Saiu da rede", é uma variável dicotômica que categoriza os professores entre aqueles que saíram da rede e aqueles que ficaram na rede. A construção dessas variáveis foi realizada a partir das bases do Magister/SME que continham, para cada docente, a data de entrada e de saída de cada lotação. Quando o docente apresentou data entrada e nenhuma saída, significa que ele permaneceu na mesma na rede até o final do período analisado, mesmo que tenha mudado de escola ao longo do tempo. Quando o professor apresenta uma data de saída, mas não tem nenhuma entrada posterior, significa que ele saiu da rede.

O quadro 2 exemplifica os tipos de movimentação possíveis observadas na base:

Quadro 2: Exemplo dos três tipos de movimentação possível na base de dados.

\begin{tabular}{|l|c|c|c|c|c|c|}
\hline & Lotação 1 & Entrada 1 & Saída 1 & Lotação 2 & Entrada 2 & Saída 2 \\
\hline Prof. A & Escola 1 & $01 / 01 / 09$ & & & & \\
\hline Prof. B & Escola 1 & $01 / 01 / 09$ & $31 / 12 / 09$ & Escola 2 & $01 / 01 / 10$ & \\
\hline Prof. C & Escola 1 & $01 / 01 / 09$ & $31 / 12 / 09$ & & & \\
\hline
\end{tabular}

Fonte: elaboração própria.

De acordo com o exemplo do quadro 2, o Prof. A permaneceu na mesma escola durante todo o período de acompanhamento, o Prof. B realizou uma mudança de escola e permaneceu nesta nova escola até o final do acompanhamento e o Prof. C saiu da rede.

A tabela 1 apresenta as estatísticas descritivas das variáveis utilizadas nos modelos de regressão estimando o risco de abandono da rede.

\section{Análise}

Em um primeiro momento, apresentaremos análises descritivas observando a proporção de professores que saíram da rede ao longo dos anos. A intenção é compreender o tamanho do fenômeno na rede.

Em seguida, utilizaremos uma regressão logística para estimar a probabilidade de um professor sair da rede considerando características dos professores e das escolas em que estão lotados. Este tipo de regressão é o indicado para análises multivariadas - ou seja, que tem mais de uma variável independente - cuja variável dependente é dicotômica (no caso da presente pesquisa saiu ou não saiu da rede). Nossa intenção aqui foi identificar fatores associados ao abandono, e desta forma estimamos o impacto de cada variável na probabilidade do docente sair ou permanecer na rede.

\footnotetext{
${ }^{5}$ De acordo com Bartholo (2014) escolaridade dos pais, cor/raça e situação de pobreza são variáveis consistentemente utilizadas em estudos nacionais e internacionais sobre segregação escolar, sendo também usadas em pesquisas sobre desigualdades educacionais. Na pesquisa da qual este artigo se origina (CARRASQUEIRA, 2018), testamos essas variáveis separadas e constatamos não haver perda no uso delas em um indicador, principalmente por não termos um foco em características específicas do corpo de discente, mas em sua composição socioeconômica e racial como um todo.
} 
Tabela 1: Estatísticas descritivas das variáveis dependente e independentes.

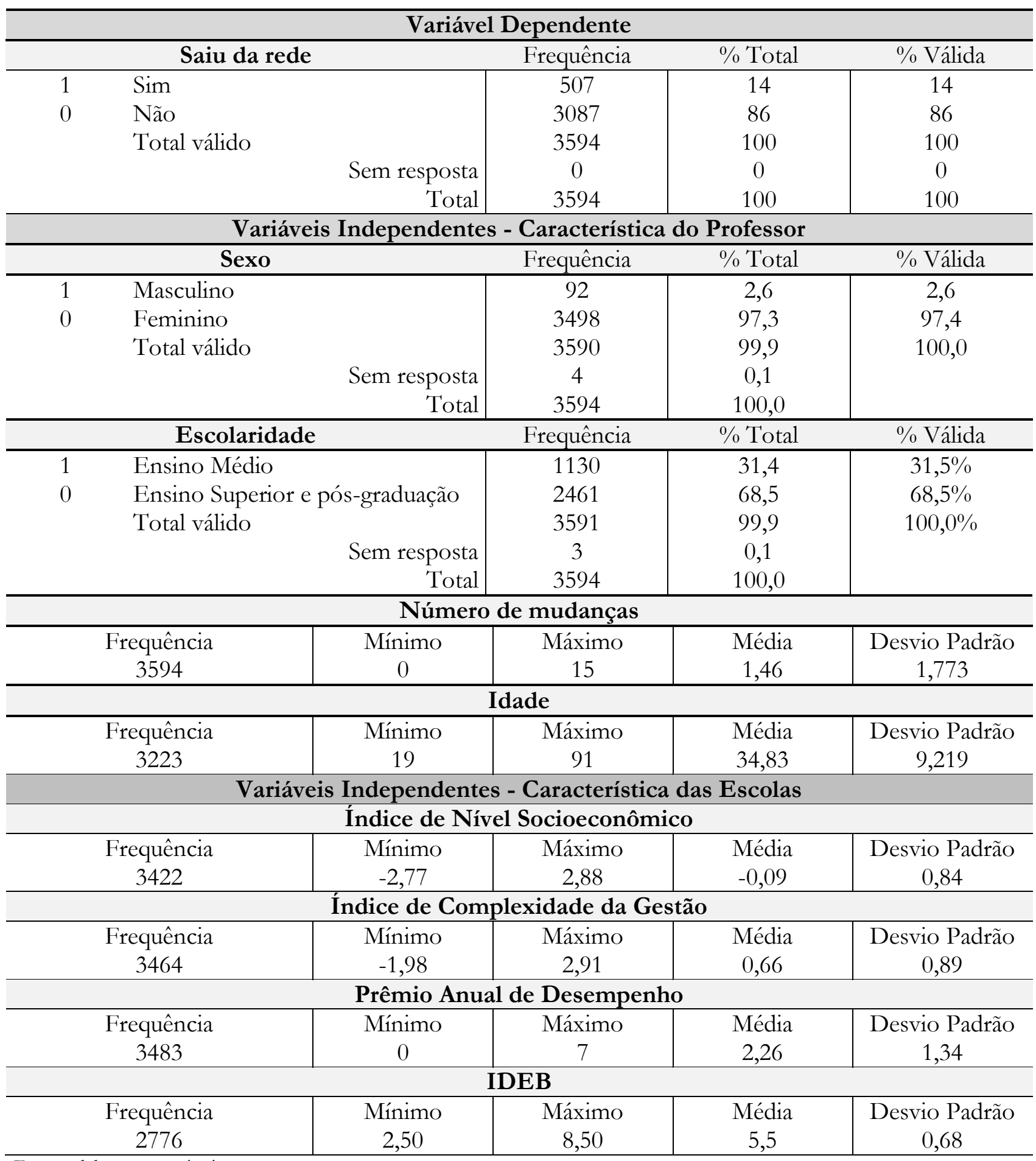

Fonte: elaboração própria.

\section{RESULTADOS}

Abandono docente se define como a saída do/a professor/a, não apenas da escola em que está lotado, mas da rede. No caso dos nossos dados, apesar de estarmos chamando de abandono, podemos ter casos de saídas esperadas, como aposentadorias ou falecimento. Como não temos acesso ao motivo que levou o docente a sair do sistema, toda saída está sendo considerada abandono. Isso significa que nossos resultados podem estar superestimados. No entanto, como consideramos somente 
os professores que ingressaram na rede nos anos de 2009, 2010 e 2011, supomos que a aposentadoria não seria um fenômeno frequente na coorte foco do estudo.

Na tabela 2, podemos ver as proporções de saída de professores ano a ano, tendo como referência os professores que estavam na rede no ano anterior.

Dos professores da coorte que tomaram posse em 2009, considerando aqueles ainda ativos no início de 2012, 5,26\% abandonaram a rede até o final de 2012. Uma taxa bem elevada, considerando que para os outros anos e para os outros grupos, as taxas de abandono em relação ao ano anterior ficaram entre $3,76 \%$ e 1,62\%. Para os três anos de posse temos uma proporção de perda média de cerca de 3\% ao ano (3,3\% para docentes que ingressaram em 2009; e 2,9\% para aqueles que ingressaram em 2010 e 2011).

Tabela 2: Proporção de saídas por ano em relação ao ano anterior, por ano de entrada na rede.

\section{Proporção de perda por ano em relação ao ano anterior ${ }^{6}$}

\begin{tabular}{|c|c|c|c|c|c|}
\hline & 2012 & 2013 & 2014 & 2015 & 2016 \\
\hline \multirow{2}{*}{2009} & $5,26 \%$ & $2,78 \%$ & $1,79 \%$ & $3,27 \%$ & $3,76 \%$ \\
\cline { 2 - 6 } 2010 & $3,05 \%$ & $2,99 \%$ & $1,62 \%$ & $3,54 \%$ & $3,25 \%$ \\
\cline { 2 - 6 } 2011 & $3,17 \%$ & $2,84 \%$ & $2,03 \%$ & $2,85 \%$ & $3,74 \%$ \\
\hline
\end{tabular}

Fonte: Magister. Elaboração própria.

Tabela 3: Proporção de saídas acumuladas entre 2012 e 2016, por ano de entrada na rede.

Proporção de perda acumulada ${ }^{7}$

\begin{tabular}{|c|c|c|c|c|c|}
\hline & 2012 & 2013 & 2014 & 2015 & 2016 \\
\hline \multirow{2}{*}{$\mathbf{2 0 0 9}$} & $5,26 \%$ & $7,89 \%$ & $9,54 \%$ & $12,50 \%$ & $15,79 \%$ \\
\cline { 2 - 6 } $\mathbf{2 0 1 0}$ & $3,05 \%$ & $5,95 \%$ & $7,47 \%$ & $10,75 \%$ & $13,64 \%$ \\
\cline { 2 - 6 } 2011 & $3,17 \%$ & $5,91 \%$ & $7,83 \%$ & $10,45 \%$ & $13,80 \%$ \\
\hline
\end{tabular}

Fonte: Magister. Elaboração própria.

Em termos de perda acumulada de professores causada pelo abandono docente, a tabela 3 mostra que, no final do período de observação, o abandono foi de 14\% do total, sendo que para o grupo que tomou posse em 2009 a perda chegou a quase 16\%, enquanto que para os outros grupos, a taxa de abandono acumulado foi parecida, ficando na casa dos 13\%. Ou seja, em apenas 5 anos a rede perdeu $14 \%$ dos professores da nossa coorte. Comparando com resultados de outros trabalhos, para o mesmo período (2009-2017), Cardoso (2018) observou uma taxa média de exoneração de professores da rede estadual de São Paulo de cerca de 11\% ao ano, com uma taxa acumulada de 35,9\%. Pereira e Oliveira (2018) realizaram análises sobre a capacidade de retenção dos docentes pelas redes municipais no Brasil utilizando os dados do Censo Escolar. Na análise de 2015-2016 eles observaram uma taxa de 0,77, o que significa que $23 \%$ dos professores que estavam em uma rede educacional em 2015 já não estavam mais naquela rede no ano seguinte. Em comparação com estudos internacionais, Geiger e Pivovarova (2018)

\footnotetext{
${ }^{6}$ Para 2012, a relação é com o total da coorte para o ano de posse correspondente.

${ }^{7}$ Para 2012 a perda não é acumulada, é a relação entre o total da coorte (professores ativos no início de 2012) e quantos professores saíram este ano.
} 
relataram uma taxa de $24 \%$ de abandono para o ano 2015 no estado do Arizona e um percentual anual médio de abandono da rede pública de Chicago de 11,7\% entre 2012-2015.

No caso desta pesquisa, estamos observando apenas um pequeno grupo de professores da rede, e, portanto, o percentual de abandono, considerando todos os docentes, nos anos observados pode ser maior. Frisando novamente que nossa análise pode estar subestimada por dados faltantes no banco, ainda assim, temos uma situação que indica que os docentes que tomaram posse em 2009 abandonaram um pouco mais do que os que entraram em 2010 e 2011. Como a diferença é pequena, pode ser uma flutuação aleatória.

A tabela 4 traz os resultados da regressão logística para estimar o abandono docente. Usamos o método de inserção em três blocos (Enter Method), o primeiro com as características dos docentes, no segundo, acrescentamos as características das escolas sem o IDEB e no terceiro, incorporamos todas as variáveis. O IDEB só foi inserido no último modelo, uma vez que diversas escolas não possuem o indicador e, portanto, as análises que incluem esta variável apresentam uma considerável perda de casos.

Tabela 4: Estimativas (e chances) dos modelos para estimar a probabilidade de o docente abandonar a rede.

\begin{tabular}{|c|c|c|c|}
\hline & Modelo 1 & Modelo 2 & Modelo 3 \\
\hline $\begin{array}{l}\text { Características do docente } \\
\text { Sexo: Feminino }\end{array}$ & $\begin{array}{c}-0,796^{* *} \\
(0,451)\end{array}$ & $\begin{array}{c}-0,833^{* *} \\
(0,435)\end{array}$ & $\begin{array}{c}-0,999 * * \\
(0,368)\end{array}$ \\
\hline Escolaridade: Ensino Superior & $\begin{array}{c}0,419 * * \\
(1,521)\end{array}$ & $\begin{array}{c}0,456^{* *} \\
(1,578)\end{array}$ & $\begin{array}{c}0,585^{* *} \\
(1,795)\end{array}$ \\
\hline Idade em anos & $\begin{array}{c}-0,038^{* *} \\
(0,962)\end{array}$ & $\begin{array}{c}-0,037 * * \\
(0,964)\end{array}$ & $\begin{array}{c}-0,045^{* *} \\
(0,956)\end{array}$ \\
\hline Quantas vezes mudou de lotação & $\begin{array}{c}-0,209 * * \\
(0,811)\end{array}$ & $\begin{array}{c}-0,202^{* *} \\
(0,817)\end{array}$ & $\begin{array}{c}-0,191 * * \\
(0,826)\end{array}$ \\
\hline $\begin{array}{l}\text { Características da escola } \\
\text { Índice de Nível Socioeconômico }\end{array}$ & & $\begin{array}{c}-0,163^{*} \\
(0,849)\end{array}$ & $\begin{array}{c}-0,207 * * \\
(0,813)\end{array}$ \\
\hline Índice de Complexidade da Gestão & & $\begin{array}{c}0,086 \\
(1,089)\end{array}$ & $\begin{array}{l}-0,140 \\
(0,870)\end{array}$ \\
\hline Prêmio Anual de Desempenho & & $\begin{array}{c}-0,347^{* *} \\
(0,706)\end{array}$ & $\begin{array}{c}-0,460 * * \\
(0,632)\end{array}$ \\
\hline IDEB & & & $\begin{array}{l}-0,104 \\
(0,901)\end{array}$ \\
\hline Constante & 0,279 & $0,888^{* *}$ & 2,263 \\
\hline Número de casos válidos na análise & 3218 & 3049 & 2440 \\
\hline $\mathrm{R}^{2}$ & 0,051 & 0,094 & 0,131 \\
\hline
\end{tabular}

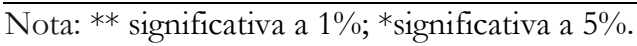

Os três modelos são consistentes tanto no que se refere ao valor e sentido dos coeficientes, quanto na significância das variáveis, com exceção da complexidade da gestão, que muda de sinal, mas que não apresenta parâmetros estatisticamente significante nos dois modelos em que foi incluída. Os resultados do modelo 3 indicam que ser mulher diminui as chances de abandono. Uma maneira de interpretar o coeficiente obtido no modelo 3 é o seguinte: os homens têm três vezes mais chances de abandonar a rede se comparados com as mulheres. Ter ensino superior aumenta a chance de sair da rede 
em 1,8 vezes se comparado com ter apenas ensino médio. $\mathrm{O}$ acréscimo de um ano de idade está associado à diminuição em cerca de 0,05 vezes a chance do docente abandonar a rede. Outra maneira de observar o efeito da idade é observar as probabilidades preditas pelo modelo 3 para docentes com 20 anos, 30 anos, 40 anos e 50 anos: as probabilidades de abandono são, respectivamente, 25\%, 18\%, 12\% e 8\%.

Cada vez que o docente mudou de lotação a chance de sair da rede diminuiu de cerca de 0,2 vez. Em termos de probabilidade predita, o docente que não realizou nenhuma migração tem 33\% de probabilidade de abandonar a rede, enquanto que os docentes que mudaram 1, 3, 6 e 10 vezes, têm probabilidade predita de $24 \%, 11 \%, 7 \%$ e $3 \%$, respectivamente, de abandonar a rede.

No que diz respeito às características da escola, ressaltamos primeiro o efeito expressivo da composição do corpo discente. O aumento de 1 ponto no INSE da escola diminui em 0,2 vez a chance de o docente sair da rede. As probabilidades preditas de abandono da rede para um docente lotado em escolas com INSE máximo (2,88), médio $(0,09)$ e mínimo (-2,77) são, respectivamente, $9 \%, 15 \%$ e 24\%. O ICG e o IDEB não são significantes, mas vale ressaltar que no modelo em que a variável IDEB foi inserida o ICG mudou de sinal, possivelmente porque nesse modelo foram automaticamente excluídas as escolas que não possuem IDEB e que, provavelmente são menores e com menor ICG. O número de vezes que a escola ganhou o PAD se mostrou não apenas significativo, mas umas das variáveis de maior impacto no abandono. Cada vez que a escola ganhou o prêmio diminuiu a probabilidade de o professor abandonar a rede em 0,4 vezes. Em termos de probabilidade predita, nas escolas que ganharam o PAD $0,1,4$ e 7 vezes, temos, respectivamente, $33 \%, 24 \%, 7 \%$ e $2 \%$ de probabilidade de o professor sair da rede.

\section{DISCUSSÃO}

Esses resultados vão ao encontro das pesquisas internacionais que indicavam que o abandono docente estava mais relacionado com características do professor do que com características da escola. Professores mais jovens e com escolaridade mais alta têm mais chance de, ao sair da rede, encontrar outra colocação no mercado de trabalho que tenha mais benefícios. A idade é a característica de maior consenso. Todos os estudos discutidos anteriormente que utilizaram essa variável indicaram que os professores que ingressam na carreira docente mais jovens são os que mais abandonam a rede (BORMAN \& DOWLING, 2008; ALLENSWORTH, PONISCIAK \& MAZZEO, 2009; BARBIERI, ROSSETTI \& SESTITO, 2010; SASS et al., 2012).

Em relação a escolaridade, apesar da meta-análise de Borman e Dowling (2008) observar que os docentes com pós-graduação abandonavam mais a rede do que os docentes que possuíam apenas o ensino superior, na rede que estamos investigando, poucos professores possuem pós-graduação no momento de ingresso na rede $(16,6 \%)$ e a escolaridade mínima para o cargo é o ensino médio. Podemos então supor que mesmo em contextos diferentes, menos escolaridade diminui as chances de sair da rede. Destaco que durante as análises descritivas, foi observado que os resultados para pós-graduação eram os mesmos que para quem tinha apenas graduação e, por isso, juntamos essas duas categorias. A explicação se dá na atratividade da carreira docente. Profissionais com mais qualificação têm mais possibilidade de se inserirem em ocupações com melhores salários e melhores condições de trabalho (LEME, 2012).

A questão do sexo pode tanto estar relacionada ao fato de o número de docentes do sexo feminino ser muito maior do que os do sexo masculino na nossa coorte, quanto por estarmos pesquisando profissionais concursados que têm a estabilidade garantida. Para mulheres, especialmente com filhos, as possibilidades do mercado de trabalho ainda são menores do que para os homens. A relação entre sexo e abandono parece depender do contexto da rede e, por isso, cada pesquisa encontrou um resultado diferente. Allensworth, Ponisciak e Mazzeo (2009) não encontraram diferença significante entre homens e mulheres na rede pública de Chicago quando a proporção entre as duas categorias era similar. Sass et al. (2012) relataram que os homens abandonam mais a rede do Texas. A meta-análise realizada por Borman e Dowling (2008) encontrou uma pequena diferença relacionada ao sexo dos professores, com as mulheres tendo mais chance de abandonar. No entanto, esses estudos foram realizados há mais de 10 anos.

As pesquisas discutidas na revisão da literatura não se propuseram a observar a relação entre a mobilidade e o abandono docente. Contudo, podemos inferir que o número de vezes que o docente muda de escola pode indicar um desejo de permanecer na rede, apenas encontrando uma escola mais 
adequada ao seu perfil. É importante ressaltar que embora este estudo tenha o professor como unidade de análise, o indicador de regularidade docente (IRD) produzido pelo INEP para o período entre 2012 e $2016^{8}$ informa que, neste período, 33\% das escolas da rede municipal do Rio de Janeiro apresentavam estabilidade do corpo docente baixa ou média-baixa, e apenas 4,3\% das unidades escolares tinham uma regularidade alta. Essa evidência indica que há na rede uma considerável rotatividade docente gerada por abandono e por mobilidade, fenômeno também observado por Carrasqueira e Koslinski, 2019.

Além disso, essa grande proporção de abandono ainda na primeira lotação possa ter relação com o discutido por Kalogrides, Loeb e Béteille (2012): quando designados para uma escola ou turma com muitos alunos com problemas de comportamento, os professores mais jovens abandonavam mais a rede do que os professores mais experientes. Isto indica que a primeira experiência do professor pode ser traumática a ponto de incidir sobre o abandono da rede ou mesmo da carreira. Isso vai ao encontro das pesquisas qualitativas que investigaram a percepção dos docentes sobre o motivo que os fizeram abandonar, tanto no Brasil (LAPO; BUENO, 2002, 2003; LEMOS, 2009; REBOLO, 2012; PAZ, 2013; SOUTO, 2013; XAVIER; BARBOSA, 2015) quanto nos EUA (GONZALEZ, BROWN \& SLATE, 2008), no Canadá (SAUVE, 2012), na Austrália (BUCHANAN et al., 2013) e nos Emirados Árabes Unidos (AL KAABI, 2005): a indisciplina dos alunos foi o fator escolar mais citado pelos docentes.

As análises indicaram uma forte associação entre o número de vezes que a escola ganhou o PAD e o abandono da rede. Podemos propor algumas hipóteses para tal associação a partir dos estudos discutidos anteriormente. Uma primeira possível explicação seria que o incentivo financeiro/bonificação salarial ajudaria a manter o docente na rede. Estudos qualitativos indicam que a questão financeira tem impacto na decisão dos professores em abandonar a rede. Entretanto, no contexto brasileiro, não encontramos estudos com foco na relação entre abandono e políticas de responsabilização. Encontramos somente um estudo que investigou o impacto dos programas de incentivo financeiro (Clotfelter, Ladd e Vidgor, 2010), mas são de um tipo diferente do investigado neste trabalho. Além disso, a bonificação salarial recebida é equivalente a um " $14^{\circ}$ salário", e pode exercer um impacto simbólico (reconhecimento de um bom trabalho), mais do que um incentivo financeiro.

Outra possível explicação para forte associação entre abandono e o PAD seria que professores em escolas que não ganham o prêmio podem estar sob maior pressão. Andrade, Koslinski e Ceneviva (2018) mostram que a pressão da política de responsabilização do município do Rio de Janeiro teve um grande impacto na probabilidade de os diretores saírem do cargo. No entanto, estudo realizado no mesmo contexto observou que os diretores de escolas com baixo desempenho nas avaliações externas - e que menos frequentemente recebem o prêmio - sentem mais esta pressão, se comparados com professores que, raramente, sentem-se pressionados (CUNHA, 2015).

Por fim, outra explicação seria que o número de vezes que a escola ganhou o PAD esteja representando outras características da escola, como por exemplo o clima escolar. Por exemplo, o estudo de Candian e Resende (2013), observou que a percepção de um bom clima escolar pelos alunos está associada a resultados melhores nas avaliações externas, indicando que escolas que propiciam um ambiente favorável ao aprendizado se mostram mais eficazes. Boyd et al (2011) que investigaram diretamente a relação entre condições de trabalho, liderança da gestão e clima escolar com o abandono docente, trazem evidências de que a percepção dos professores sobre essas características das escolas podem ser os fatores mais relevantes na decisão do docente abandonar a escola, a rede ou o magistério. O estudo de Geiger e Pivovarova (2018), especialmente, nos mostra que as condições de trabalho e/ou o clima escolar podem ter mais relação com o abandono do que as características do corpo discente. No entanto, Brito e Costa (2010) argumentam que a percepção dos professores sobre o clima escolar impacta no trabalho docente, que adaptam suas práticas de acordo com o seu alunado, podendo reproduzir desigualdades educacionais (BRITO \& COSTA, 2010). Na mesma direção, Harker e Tymms (2004) argumentam que o efeito da composição dos alunos não necessariamente se resume à interação entre pares e pode refletir a interação entre a composição do alunado e ação do professor, clima escolar,

\footnotetext{
${ }^{8}$ Este indicador realiza o cálculo da estabilidade para o par escola-professor no período de 5 anos, a partir dos dados do Censo Escolar (INEP, 2015). Assim, o IRD de 2016 considera a estabilidade dos professores nas escolas entre 2012 e 2016. O indicador é padronizado para o intervalo entre 0 (total irregularidade) e 5 (total regularidade) e divulgado como média no nível da escola, do município, do estado, da região ou do país. Não há separação entre segmentos, apenas de dependência administrativa.
} 
envolvimento dos pais, comprometimento dos professores entre outros. Isto é, alunos reagem às estruturas/processos escolares e a seus pares e as escolas, por sua vez, reagem à composição do alunado. Assim, a relação entre clima escolar e abandono docente pode ser mediada pela reação dos professores às características socioeconômicas e/ou composição racial dos alunos.

\section{CONSIDERAÇÕES FINAIS}

Este trabalho traz uma contribuição inédita para a discussão do tema no contexto brasileiro, uma vez que identificou fatores individuais e relacionados ao contexto escolar associados ao abandono da rede a partir do uso de metodologia quantitativa. Esta contribuição singular foi possível frente ao acesso a bases de dados da Secretaria Municipal de Educação que permitiram acompanhar todas as mudanças de lotação realizadas por cada docente da rede.

Desta forma, conseguimos verificar que os professores com maior probabilidade de abandonar a rede municipal do Rio de Janeiro são os mais jovens e mais escolarizados, indicando, como outras pesquisas brasileiras e internacionais, que a carreira docente parece pouco atrativa para professores mais jovens e mais qualificados. No livro sobre os egressos da UFMG organizado por Las Casas, Cunha e Queiroz (2019) fica bastante evidente que os profissionais que permanecem como professores da educação básica são, em geral, filhos de famílias de baixo capital econômico e que tiveram no magistério uma possibilidade de mobilidade social. Ainda assim, o sentimento de desprestígio da profissão fica bastante marcado em algumas das pesquisas apresentadas.

Contudo, para além da baixa atratividade do magistério, as características do corpo discente também podem ser importantes para o professor abandonar a rede. O desinteresse, a indisciplina e a violência dos alunos são fatores sempre citados por ex-docentes nas pesquisas brasileiras. No entanto, o alto impacto do PAD, nos trouxe à luz a influência das políticas de responsabilização escolar e de fatores contextuais da escola, muito pouco explorados pelas pesquisas no Brasil.

No entanto, vale ressaltar que, mesmo frente às limitações das bases de dados e da opção de recorte utilizadas no presente estudo, os dados encontrados indicam uma menor taxa de abandono na rede municipal do Rio de Janeiro, se comparada com estudos realizados em outras redes municipais brasileiras. Neste sentido, estudos futuros podem concentrar seus esforços não somente em identificar características das escolas, como clima escolar/liderança da gestão, associados ao abandono, como também, a partir de recortes mais abrangentes, observar características das redes e de suas políticas (salário, plano de carreiras, regras de alocação de professores recém concursados, programas de apoio ou tutoria de professores que ingressam na rede, entre outros) que incidem sobre as condições do trabalho docente e, consequentemente, abandono. Os resultados dos estudos propostos podem melhor informar políticas educacionais baseadas em evidências com foco na atração e retenção de professores mais qualificados para a profissão docente.

Por fim, é importante também, que pesquisas no Brasil deem um passo além e investiguem o impacto do abandono docente para a aprendizagem dos alunos, em especial daqueles em situação de vulnerabilidade social e de baixo desempenho. Tais estudos podem indicar que a adoção de políticas que visam a retenção dos professores mais qualificados pode exercer um impacto não somente na eficácia, como também na equidade dentro das redes de ensino.

\section{REFERÊNCIAS}

ANDRADE, Felipe. M.; KOSLINSKI, Mariane. C.; CENEVIVA, Ricardo. Fatores associados à rotatividade de diretores no município do Rio de Janeiro. Educação em Revista, v. 34, p. 1-26, 2018.

AL KAABI, Ali S. Factors influencing teacher attrition in the United Arab Emirates. 2005. Dissertation (PhD in Education) - Graduate Faculty of School of Education, University of Pittsburgh. Pittsburgh, 2005. 
ALLENSWORTH, Elaine; PONISCIAK, Stephen; MAZZEO, Christopher. The schools teachers leave: mobility in Chicago public schools. (Research Report) Consortium on Chicago School Research at the University of Chicago Urban Education Institute. Chicago, 2009.

ALVES, Luciana et al. Desigualdades socioespaciais e concorrência entre professores por escolas. In: $36^{a}$ REUNIÃO NACIONAL DA ANPED, 36, 2013, Goiânia. Anais Eletrônicos da 36ª Reunião Nacional da ANPEd, Goiânia: UFG, 2013. Disponível em: http://36reuniao.anped.org.br/pdfs_trabalhos_aprovados/gt14_trabalhos_pdfs/gt14_3199_texto.pdf

ATTEBERRY, Allison; LOEB, Susanna; WYCKOFF, James. Teacher Churning: Reassignment Rates and Implications for Student Achievement. Educational Evaluation and Policy Analysis, v. 39, n. 1, p. 3-30, 2017.

ÁVALOS, Beatrice; VALENZUELA, Juan Pablo. Education for all and attrition/retention of new teachers: A trajectory study in Chile. International Journal of Educational Development, v. 49, p. 279-290, 2016.

BARBIERI, Gianna; ROSSETTI, Claudio; SESTITO, Paolo. The determinants of teacher mobility: evidence from a panel of Italian teachers. Banca D'Italia, 2010. (Working Paper n.761).

BARBOSA, Andreza. Os salários dos professores brasileiros: implicações para o trabalho docente. 2011. Tese (Doutorado em Educação Escolar) - Faculdade de Ciências e Letras, Universidade Estadual Paulista. Araraquara, 2011.

BARTHOLO, Tiago. L. Segregação escolar na cidade do Rio de Janeiro: análise da movimentação de estudantes. Estudos em Avaliação Educacional, São Paulo, v. 25, n. 58, p. 242-271, maio/ago., 2014.

BORMAN, Geoffrey D.; DOWLING, Maritza. Teacher attrition and retention: a meta-analytic and narrative review of the research. Review of Educational Research, v. 78, p. 367-409, sep. 2008.

BOYD, Donald et al. The influence of school administrators on teacher retention decisions. American Educational Research Journal, v. 48, n. 2, p. 303-333, 2011.

BOYD, Donald et al. Who leaves? Teacher attrition and student achievement. Cambridge: National Bureau of Economic Research, 2008. (NBER Working Paper 14022). Disponível em: http://www.nber.org/papers/w14022

BRITO, Márcia D. S. T.; COSTA, Márcio. Práticas e percepções docentes e suas relações com o prestígio e clima escolar das escolas públicas do município do Rio de Janeiro. Revista Brasileira de Educação, v. 15, n. 45, p. 500-510, set./dez. 2010.

BUCHANAN, Jonh et al. Teacher retention and attrition: views of early career teachers. Australian Journal of Teacher Education, v. 38, n. 3, p. 112-129, 2013.

CANDIAN, Juliana F.; REZENDE, Wagner S. O contexto normativo do clima escola e o desempenho dos alunos: implicações para o debate sobre gestão escolar. Pesquisa e Debate em Educação, v. 3, p. 25-41, 2013. 
CARDOSO, Walassy. C. Adeus magistério: O abandono dos professores de Sociologia da Rede Estadual de Ensino de São Paulo. 2018. Monografia (Bacharelado e Licenciatura em Ciência Sociais) Universidade Federal de São Paulo, 2018.

CARLOTTTO, Mary Sandra; CÂMARA, Sheila G.; OLIVEIRA, Michelle E. T. Intenção de abandono profissional entre professores: o papel dos estressores ocupacionais. Revista Brasileira de Educação, v. 24, p. 1-18, 2019.

CARRASQUEIRA, Karina. A política de responsabilização educacional do município do Rio de Janeiro. 2013. Dissertação (Mestrado em Educação) - Programa de Pós-Graduação em Educação, Universidade Federal do Rio de Janeiro, Rio de Janeiro, 2013.

CARRASQUEIRA, Karina. Fatores associados ao abandono e à mobilidade docente na rede municipal do Rio de Janeiro. 2018. Tese (Doutorado em Educação) - Programa de Pós-Graduação em Educação, Universidade Federal do Rio de Janeiro, Rio de Janeiro, 2018.

CARRASQUEIRA, Karina; KOSLINSKI, Mariane C. Fatores associados à mobilidade docente no município do Rio de Janeiro. Cadernos de Pesquisa, São Paulo, v. 49, n. 173, p. 106-129, jul./set. 2019. https://doi.org/10.1590/198053146014

CLOTFELTER, Charles T.; LADD, Helen. F.; VIGDOR, Jacob L. Teacher mobility, school segregation, and pay-based policies to level the playing field. Washington, D.C.: National Center for Analysis of Longitudinal Data in Education Research, 2010 (Working Paper 44). Disponível em: https://caldercenter.org/publications.

CUNHA, Carolina P. Prática docente sob pressão: ações e percepções de professores sobre a política de responsabilização na rede municipal de Ensino do Rio de Janeiro. 2015. Dissertação (Mestrado em Educação) - Universidade Federal do Rio de Janeiro, Rio de Janeiro.

DUPRIEZ, Vincent; DELVAUX, Bernard; LOTHAIRE, Sandrine. Teacher shortage and attrition: Why do they leave? British Educational Research Journal, v. 42, n. 1, p. 21-39, 2016.

GEIGER, Tray; PIVOVAROVA, Margarita. The effects of working conditions on teacher retention. Teachers and Teaching: Theory and Practice, v. 24, n. 6, p. 604-625, 2018.

GONZALEZ, Lisa; BROWN, Michelle S.; SLATE, John R. Teachers who left the teaching profession: a qualitative understanding. The Qualitative Report, v. 13, n. 1, p. 1-11, 2008.

HANUSHEK, Eric A. et al. The market for teacher quality. Cambridge: National Bureau of Economic Research, 2005. (NBER Working Paper 11154). Disponível em: http://www.nber.org/papers/w11154

HARKER, Richard; TYMMS, Peter. The Effects of Student Composition on School Outcomes. School Effectiveness and School Improvement: An International Journal of Research, Policy and Practice, 15(2), 177-199, 2004. 
INSTITUTO NACIONAL DE ESTUDOS E PESQUISAS EDUCACIONAIS ANÍSIO TEIXEIRA (INEP). Nota Técnica CGCQTI/DEED/INEP nº 11 de 25 de junho de 2015.

KALOGRIDES, Demetra; LOEB, Susanna; BÉTEILLE, Tara. Systematic sorting: teacher characteristics and class assignments. Sociology of Education, v. 86, n. 2, p. 103-123, 2012.

KASMIRSKI, Paula. R. Mobilidade de professores na rede estadual paulista. 2012. Dissertação (Mestrado em Economia) - Faculdade de Economia, Administração e Contabilidade, Universidade de São Paulo, 2012.

LADD, Helen. F. Teachers' Perceptions of their Working Conditions: How Predictive of Planned and Actual teacher Movement? Educational Evaluation and Policy Analysis, v. 33, n. 2, p. 235-261, 2011.

LAS CASAS, Estevam. B.; CUNHA, Daisy; QUEIROZ, Tatiana. UFMG pesquisa egressos. Belo Horizonte: Editora UFMG, 2019.

LAPO, Flavinês R.; BUENO, Belmira O. O Abandono do Magistério: Vínculos e Rupturas com Trabalho Docente. Psicologia USP, v. 13, n. 2, p. 243-276, 2002.

LAPO, Flavinês R.; BUENO, Belmira O. Professores, desencanto com a profissão e abandono do magistério. Cadernos de Pesquisa, n. 118, p. 65-88, 2003.

LEME, Luciana F. Atratividade do magistério para a educação básica: estudo com ingressantes de cursos superiores da Universidade de São Paulo. 2012. Dissertação (Mestrado em Educação) Faculdade de Educação, Universidade de São Paulo. São Paulo, 2012.

LEMOS, José Carlos G. Do encanto ao desencanto, da permanência ao abandono: o trabalho docente e a construção da identidade profissional. 2009. Tese (Doutorado em Educação) - Programa de Estudos Pós-Graduados em Educação, Pontifícia Universidade Católica de São Paulo. São Paulo, 2009.

LOUZANO, Paula et al. Quem quer ser professor? Atratividade, seleção e formação docente no Brasil. Estudos em Avaliação Educacional, v. 21, n. 47, p. 543-568, 2008.

MANSFIELD, Richard K. Teacher quality and student inequality [versão eletrônica]. Cornell University, ILR School, 2012. Disponível em: https://digitalcommons.ilr.cornell.edu/workingpapers/162/

MASSON, Gisele. Des exigences essentielles pour l'attractivité et la permanence dans la carrière d'enseignant. Educação e Sociedade, v. 38, n. 140, p. 849-864, 2017.

PAZ, Mônica L. A permanência e o abandono da profissão docente entre professores de matemática. 2013. Tese (Doutorado em Educaçao) - Programa de Pós-Graduação em Educação, Universidade Federal de Minas Gerais, 2013.

PEREIRA, Edmilson A.; OLIVEIRA, Dalila A. Indicadores de retenção e rotatividade dos docentes da Educação Básica. Cadernos de Pesquisa, v. 46, n. 160, p. 312-332, 2016. 
PEREIRA, Edmilson A.; OLIVEIRA, Dalila A. Retention and teacher rotation in municipal education networks in Brazil. Praxis Educativa, v. 13, n. 3, p. 734-749, 2018.

REBOLO, Flavinês. Do mal-estar docente ao abandono da profissão professor: a história de Estela. Série-Estudos, Campo Grande, n. 33, p. 143-163, 2012.

RONFELDT, Matthew; MCQUEEN, Kiel. Does New Teacher Induction Really Improve Retention? Journal of Teacher Education, v. 68, n. 4, p. 394-410, 2017.

RONFELDT, Matthew et al. How teacher turnover harms student achievement. Cambridge: National Bureau of Economic Research, 2011. (NBER Working Paper 17176). Disponível em: http://www.nber.org/papers/w17176

RONFELDT, Matthew; LOEB, Susanna; WYCKOFF, James. How Teacher Turnover Harms Student Achievement. American Educational Research Journal, v. 50, n. 1, p. 4-36, 2013.

RYAN, Shannon. V. et al. Leaving the teaching profession: The role of teacher stress and educational accountability policies on turnover intent. Teaching and Teacher Education, v. 66, p. 1-11, 2017.

SASS, Daniel. A. et al. Indentifying personal and contextual factors that contribute to attrition rates for Texas Public School teachers. Education Policy Analysis Archives, v. 20, n. 15, p. 1-26, 2012.

SAUVÉ, Frédéric. Analyse de l'attrition des enseignants au Québec. 2012. Mémoire (M.A. en administration et fondements de l'éducation), Faculté des Sciences de l'éducation, Université de Montréal, 2012.

SOUTO, Romélia. M. A. O abandono do magistério entre os professores egressos da licenciatura em matemática da UFSJ - indícios sobre a condição docente no Brasil. In: VII CIBEM, 8, 2013, Montevideo. Actas del VII CIBEM, Montevideo: Colegio Seminario, 2013. Disponível em: http://cibem.semur.edu.uy/7/actas/pdfs/257.pdf

TORRES, Haroldo G. et al. Educação na periferia de São Paulo: ou como pensar as desigualdades educacionais? In: RIBEIRO, L. C. D. Q.; KAZTMAN, R. A cidade contra a escola? Segregação urbana e desigualdades educacionais em grandes cidades da América Latina. Rio de Janeiro: Letra Capital: FAPERJ; Montevideo: IPPES, 2008. p. 59-90.

WEST, Martin R.; CHINGOS, Matthew. M. Teacher effectiveness, mobility and attrition in Florida. In: SPRINGER, M. G. (ed.). Performance Incentives: Their growing impact on American K-12 education. Brookings Institution Press, 2009.

XAVIER, João Paulo; BARBOSA, Adriana F. Indisciplina, hostilidade no ambiente. Palimpsesto, Rio de Janeiro, v. 14, n. 3, p. 385-397, 2015. 